Gênero, Saúde, Corporeidades

\title{
Gênero e sexualidade em Saúde Coletiva: elementos para a discussão acerca da produção do cuidado integral ao usuário masculino*
}

\author{
Francisco Anderson Carvalho de Lima ${ }^{(a)}$ \\ Jonas Torres Medeiros ${ }^{(b)}$ \\ Túlio Batista Franco(c) \\ Maria Salete Bessa Jorge(d)
}

Lima FAC, Medeiros JT, Franco TB, Jorge MSB. Gender and sexuality in Collective Health: elements for the debate on the production of comprehensive care directed to the male patient. Interface (Botucatu). 2018; 22(64):29-41.

Ensuring comprehensive health care tomale users has been a major challenge in the context of Collective Health. The intention of this paper is to mapout males in order to bring contributions to health care production directed towards the male user at the same time analyzing the formal health service. Deleuze's, Guattari's, Foucault's and Rolnik's works were used to ground mapping, discursivity, and subjectivization. The user-guide approach is used to map out the itinerary through formal and informal networks thus unraveling the processes related to male subjectivization. From these bases we highlight the importance of the power of the body in providing care in living networks, the comprehension of multiplicity $(n-1)$ as materialized on the individuality of care in the potency of affection, the need for reinvention of the clinic, as well as the urgency to deepen the discussions on gender and sexuality in collective health.

Keywords: Gender and health. Men's health. Micropolitics.
A garantia da atenção integral ao usuário masculino tem se mostrado um grande desafio no contexto da Saúde Coletiva. Pretendeu-se cartografar o macho a fim de trazer aportes sobre a produção do cuidado ao usuário masculino e, com isso, pôr em análise o serviço formal de saúde. Fundamentou-se em Deleuze, Guattari, Foucault e Rolnik para se pensar cartografia, discursividade e subjetivação. Utiliza-se o dispositivo do usuário-guia para cartografar as redes percorridas formais e informais e se desvelar os processos relacionados a modos de subjetivação masculina. A partir disso, afirma-se a importância da potência do corpo na produção do cuidado nas redes vivas, a compreensão da multiplicidade ( $n-1)$ materializada na individualidade do cuidado na potência do afeto e a necessidade de reinvenção da clínica, bem como a urgência do aprofundamento das discussões sobre gênero e sexualidade em Saúde Coletiva.

Palavras-chave: Gênero e saúde. Saúde do homem. Micropolítica.
"Elaborado com base nos resultados finais do Trabalho de Conclusão de Curso em Psicologia Elementos Cartográficos do Macho: apontamentos sobre a(s) sexualidade(s) masculina(s) e gênero a partir da atenção oncológica de Fortaleza - um ensaio sobre a potência do corpo.

(a) Programa de Pós-Graduação em Avaliação de Políticas Públicas, Universidade Federal do Ceará. Av. Mister Hull, 2977, Campus do Pici, Bloco 860. Fortaleza, CE, Brasil. 60356-001. acarvalho.eco@gmail.com

(b) Instituto Federal de Educação, Ciência e Tecnologia do Ceará. Umirim, CE, Brasil. jonas.medeiros@ifce.edu.br (c) Departamento de Planejamento em Saúde, Instituto de Saúde Coletiva, Universidade Federal Fluminense. Niterói, RJ, Brasil. tuliofranco@id.uff.br (d) Programa de PósGraduação em Saúde Coletiva, Núcleo de Pesquisa e Inovação em Saúde Coletiva, Centro de Ciências da Saúde,

Universidade Estadual do

Ceará. Fortaleza, CE, Brasil. maria.salete.jorge@ gmail.com 


\section{Introdução}

Um desafio contemporâneo da Saúde Coletiva no Brasil é a promoção da saúde ao público masculino. Há necessidades específicas relacionadas ao processo de subjetivação capitalística e ao dispositivo da sexualidade masculina, que devem ser consideradas pela atenção à saúde. No Brasil, em 2014, homens jovens apresentavam 4,7 vezes mais chances de morrerem do que mulheres com a mesma idade ${ }^{2}$.

Estudos apontam problemáticas na inserção dos homens nas redes de atenção à saúde - em especial em nível de atenção primária, relacionando o aspecto da socialização masculina engendrada pelo patriarcalismo e pelo machismo - que acabam por interferir de maneira negativa no processo de cuidado, acarretando problemas como a negligência do cuidado de si, a desresponsabilização com o processo de saúde e a violência de gênero, entre outros ${ }^{3-6}$.

Diante disso, é lançado em 2009 o Plano Nacional de Atenção Integral à Saúde do Homem (PNAISH), objetivando reduzir a morbimortalidade masculina e empreender ações que insiram o homem no cotidiano dos serviços de saúde, sobretudo na atenção primária, diminuindo custos e aumentando a efetividade das ações. Objetiva, também, qualificar os profissionais de saúde para o atendimento ao público masculino, promovendo ações que acompanhem a singularidade desse público, e orientar homens e familiares acerca de promoção e prevenção de saúde, por meio da implantação de assistência em saúde sexual e reprodutiva?.

Todavia, em que medida as proposições dessa política tem contribuído efetivamente para a compreensão da categoria "homem"? Estudos ${ }^{3-6}$ apontam a necessidade do constante aperfeiçoamento e modificação da política e das ações dela advindas; pois, mesmo após a sua implementação, aspectos urgentes como a procura e a participação dos homens nos serviços de saúde continuam baixos ${ }^{8-10}$. Além disso, como a implementação dessa política tem contribuído ou pode contribuir com os processos de cuidado masculinos em âmbito micropolítico?

Diante disso, pretendemos discutir os processos de subjetivação masculina e suas implicações para o cuidado em saúde a partir da experiência viva de um usuário-guia com câncer nas redes de atenção à saúde do município de Fortaleza, Ceará, atravessado de diversas maneiras pelas masculinizações, elemento fundamental na constituição de sua rede viva de cuidado. Fazemos uso, neste estudo, do termo subjetivação por expressar um processo que não se reduz a um dado ou ponto de partida essencial. Daí a importância do estudo das linhas, isto é, das relações de forças de sentidos em que nos tecemos em sociedade e mundo e que também nos escapam, esboçando assim outras experiências de sentido ou simplesmente caotizando as já formadas.

A influência do pensamento de Foucault pelos autores que fundamentam nosso trabalho, em particular por Deleuze ${ }^{11}$, é muito fecunda para essa articulação entre as concepções de subjetividade e sociedade. Assim, tomamos como referência as proposições de Deleuze e Guattari sobre os processos de subjetivação e utilizamos a noção de "dispositivo da sexualidade" de Foucault, sendo que esses elementos constituem análise sobre as práticas discursivas e, por conseguinte, sobre o cuidado em saúde. Investigamos a micropolítica do cuidado nas Redes de Atenção à Saúde do município de Fortaleza por meio do acompanhamento cartográfico de um usuário-guia e, a partir disso, elencamos a categoria do macho - operado na máquina masculina - para ser (des)territorializada e desenvolvemos construtos que observamos reverberar no agenciamento do cuidado: Corpo sem Órgãos (CsO), afecção, potência - uma invenção da clínica e uma reinvenção de redes ${ }^{12}$.

Entendemos que o trabalho em saúde é processual e agenciado e se dá em ato, no encontro ${ }^{13}$. Dessa maneira, o desenho de uma rede de cuidado acontece por meio de intencionalidades e de potências afetivas, determinando a reinvenção de uma clínica que dê conta dos aspectos afetivos e que considere o corpo enquanto uma potência e algo que expande em direção às paixões, que muitas vezes foge ao modelo de saúde a priori desenhado e oferecido ${ }^{12}$. O que percebemos com isso é o irromper da noção de trabalho criativo, que configura diversos processos de saúde e subjetividade relacionados às concepções de liberdade e autogestão do trabalho ${ }^{14}$. Um processo assim pode nos levar a um agenciamento de cuidado que procure investir na potência do usuário e de seu corpo.

Entendemos que um dos pilares da Saúde Coletiva é a interlocução da Saúde Pública com as ciências humanas a fim de inventar processos determinantes de cuidados e mudanças de práticas. 
Assim, a contribuição deste trabalho vai no sentido de analisar a produção do cuidado ao paciente masculino por meio da investigação micropolítica dos processos de masculinidade por meio da cartografia $^{15}$, o que configura caráter inovador nas pesquisas qualitativas sobre saúde masculina.

\section{Processo metodológico}

Este trabalho compõe os resultados parciais da pesquisa compartilhada 'Observatório nacional da produção de cuidado em diferentes modalidades à luz do processo de implantação das Redes Temáticas de Atenção à Saúde no SUS: avalia quem pede, quem faz e quem usa', financiada pelo Ministério da Saúde e aprovada por comitê de ética.

Configura-se como de caráter qualitativo de natureza cartográfica e ancora-se nos desvelamentos que irrompem na produção de dados, o qual se dá em ato, no trabalho vivo, em plano existencial. Falar sobre avaliação da produção do cuidado e da micropolítica requer aspectos metodológicos que transcendem a ideia tradicional de pesquisa e cientificidade. Estudos cartográficos na área da Saúde Coletiva têm se mostrado eficazes na apreensão de elementos contingenciais sobre as vivências humanas e sobre o tecido social, proporcionando experiências inovadoras de pesquisa ${ }^{16,17}$. Cartografia é um termo oriundo da Geografia e assevera um registro do mundo paisagístico que comporta a natureza, um desenho do tempo. Deleuze e Guattari ${ }^{15}$ agenciam esse conceito de modo a reterritorializá-lo enquanto paisagens psicossociais cartografáveis em uma perspectiva que circunscreve uma relação horizontal entre pesquisador e objeto.

Como demarcador geral do rumo a se tomar na pesquisa, elencamos o ato de cartografar o "macho" e avaliar de que maneira as relações identitárias reverberam no cuidado em saúde e, com isso, avaliamos a produção do cuidado em saúde no âmbito das Redes de Atenção à Saúde na perspectiva da micropolítica, pondo o serviço em análise.

Utilizamos o encontro como ferramenta de produção de dados, por meio da implementação de instrumentos conceituais e dispositivos que operam os enunciados no processo de contaminação com os territórios, isto é, uma inserção no cotidiano de trabalho de profissionais de saúde em âmbito micropolítico. Utilizamos, também, o construto metodológico do usuário-guia, que diz respeito ao acompanhamento intensivo e potente de um sujeito, verbo-corpo-alma, em sua história de vida e em suas técnicas de cuidado, por meio da narrativa e espaços de encontro. Como usuário-guia, entendemos o sujeito nômade sobre o qual nos dedicamos a acompanhar a operação de sua narrativa como história de vida e que é trabalhado na contação de sua história, procurando-se identificar alguns demarcadores que dizem respeito à sua cartografia. Além disso, empregamos o fluxograma analisador ${ }^{13}$ como ferramenta para lançar disparadores de análise.

Em suma, 1) adentramos o campo em oficinas de produção de dados com equipes de profissionais dos três níveis de atenção para a escolha de um usuário-guia; 2 ) houve uma tentativa de promover uma (des)territorialização ${ }^{18}$ no encontro com um sujeito potente que participou ativamente em diversas associações, desenhando e operando sua rede de cuidado (o que fizemos foi meramente nos deixar contaminar com o fluxo desse sujeito e desenhar seu caminhar); 3) demarcaram-se continuamente os rumos seguidos pelo desejo do sujeito em estudo, em seu fluxo ou aprisionamento, repercutindo em suas relações, conforme as linhas que compõem o mapa de sua realidade; 4) por fim, diagramou-se um fluxograma analisador que nos forneceu pistas indicando para onde deveríamos ir e voltarmos para a compreensão do estudo. Convém asseverar que o processo de pesquisa não seguiu necessariamente a ordem numérica aqui estabelecida, cujo fim é de facilitar a compreensão do leitor; e vale ressaltar o incessante processo de leitura e os estudos em grupo ocorridos, bem como as partilhas com os outros grupos envolvidos, o que foi fundamental para a consecução do estudo.

Esse processo imanente de produção de dados se deu no território do município de Fortaleza e de sua região metropolitana, na Atenção Básica e em uma unidade privada de alta complexidade especializada no tratamento de câncer que atende grande parte dos usuários a partir de convênio com o SUS. Além do grupo de pesquisadores, graduandos, mestrandos e pós-doutorandos, houve a participação efetiva de profissionais da equipe multidisciplinar; de gestores de unidades de saúde da 
atenção básica e da atenção especializada; do usuário-guia; e dos sujeitos que acompanharam o último durante a pesquisa.

Como estratégia para a produção dos conhecimentos analisados, nos debruçamos nas narrativas de todos os atores envolvidos. Como narrativa, entendemos o ato de narrar no âmbito da imanência da enunciação - não simplesmente o fato de dizer. A narrativa, então, compreende a interseção na produção do conhecimento ${ }^{19,20}$ de maneira indutiva e imanente. Estivemos sendo infectados e contaminando o ambiente - o aspecto de narrativa compreende essa interlocução entre o pesquisador e a construção plástica do vivido, seja por meio de entrevistas, conversas, diálogos ou o contato silencioso. Utilizamos, ainda, um diário de campo, que diz respeito ao registro do cartógrafo enquanto antropófago ${ }^{18}$. A partir desses registros, pudemos ruminar todo o conhecimento em processo, bem como que afetos vinham sendo operados e, com isso, pudemos delimitar os rumos a se seguir e os afluentes que se encontravam na correnteza imanente de subjetivação.

\section{Pretensa cartografia do macho: o "cabra-macho" na óptica do cuidado em rede}

O usuário-guia autointitulado "sujeito-homem" foi eleito a partir de uma oficina no hospital privado de referência no tratamento do câncer no município de Fortaleza. O usuário é pai da fisioterapeuta da equipe e percebeu-se que este tensiona peculiarmente a equipe de profissionais, envolvendo aspectos diferenciados à dinâmica de cuidado.

A construção do desenho do usuário-guia e sua conseguinte antropofagia iniciaram-se com o entusiasmo em participar da pesquisa por parte da profissional fisioterapeuta filha deste, agenciando os pesquisadores em territórios nos quais decalcavam e desvelavam os devires presentes nos processos identificados e vivenciados. Contudo, o ponto peculiar que demarcou a eleição deste usuário foi a questão do arquétipo do macho presente nas narrativas apreendidas.

\section{Personagens}

Sujeito-homem, usuário-guia

Alva, profissional fisioterapeuta filha do usuário-guia

Maria, ex-companheira do usuário-guia e mãe de Alva

Josefa, atual companheira

Eliana, irmã

Dr. Assis, médico do hospital pesquisado

Anderson, pesquisador

Para dar prosseguimento, apresentamos uma diagramação do usuário-guia e de sua vivência de cuidado (Figura 1).

\section{Vivenciando os territórios de cuidado}

O usuário-guia tem 79 anos de idade e reside na região metropolitana de Fortaleza. Foi caminhoneiro e hoje é aposentado. Em uma parte do terreno de sua casa, vive Josefa, sua atual companheira, que administra uma creche nesse local. Ela pagava aluguel sobre esse terreno e prédio, mas atualmente não paga mais nada. Sobre isso, durante a oficina, as assistentes sociais, amigas de Alva, pronunciaram "é, ela tá com ele pra não pagar mais aluguel [risos]", o que demonstrou determinado posicionamento da equipe e de Alva, a filha, com relação ao caso do usuário-guia. $O$ primeiro contato foi por meio da visita à residência do usuário-guia, após a oficina com a equipe e entrevista com Alva no hospital. À primeira vista, o que vem à tona é a relação existente entre a profissional e o usuário, de filha-pai. 

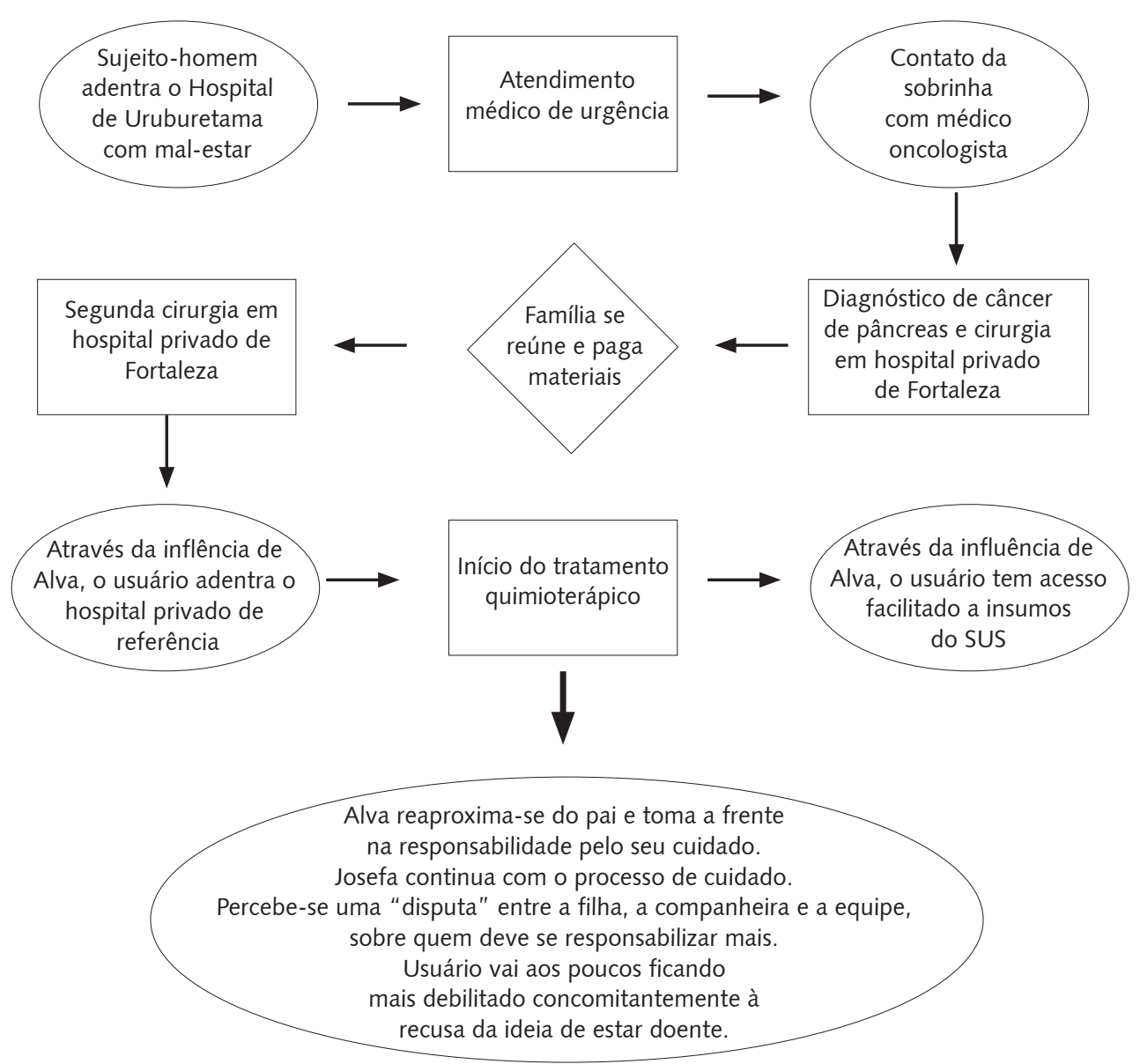

Figura 1. Diagrama analisador

Fonte: Adaptado de Lima'1.

Já o início do relacionamento do sujeito-homem com Josefa se deu a partir de investidas à sua inquilina:

Eu sou meio bruto [...] aí um dia ela veio aqui me perguntar se eu conhecia alguma casa de praia pra alugar pra ela fazer uma festa com o pessoal dela e eu falei "tá me achando com cara de corretor de imóveis?". Mas lembrei que minha irmã tem uma casa na Taíba e pensei "ela tá aí, né, vou aqui jogar um verde, vai que dá certo", aí cheguei pra ela e disse "olha, sou corretor de imóveis não, mas se você quiser tenho uma casa aqui à disposição, qualquer momento que você quiser pode ir lá". Aí arrumei e ela foi pra lá e fui também com a minha irmã, lá deu certo [risos]. (Sujeito-homem) 
O relacionamento dos dois iniciou-se em meados de novembro de 2014, quase um mês antes da crise que levou sujeito-homem ao hospital.

A partir do fluxograma anteriormente apresentado, adaptado de Merhy ${ }^{13}$, percebemos características do processo oncológico e do processo masculino de saúde: não há em nenhum momento vivência do usuário na atenção básica, que deveria ser a ordenadora do cuidado. O cuidado oncológico que se dá por via de alta complexidade - e não na atenção básica - traz maiores gastos com o tratamento e reduz as possibilidades de atuação quanto à prevenção ${ }^{21}$. Isso se relaciona com a própria história de vida desse usuário, que opera por meio de um ideário de não adoecimento e imunidade:

Eu sou sujeito-homem, rapaz, essa doença nem passou aqui e eu nunca andei em negócio de saúde porque num preciso disso, não. (Sujeito-homem)

Elas ficam dizendo aí pra eu fazer as coisas, mas eu sou macho, quando eu quero eu faço e vou ficar bom. (Sujeito-homem)

A gente tenta orientar e acompanhar ele pra fazer as coisas direito, mas ele não quer se cuidar, acha que é blindado, nunca foi atrás de cuidar da saúde com nada [...] mas ao mesmo tempo é muito sadio, muito forte [...] quando eu era criança achava que ele era um tipo de superhomem, cresci com essa imagem na cabeça, que ele sempre passa pra gente. (Alva)

Tais aspectos convergem com a ideia de subjetivação masculina que, com relação à saúde, aponta para uma negligência com relação ao cuidado de si $^{22}$. Sobre isso, convém nos debruçarmos sobre os regimes de enunciabilidade que configuram a cartografia dessa figura masculina: afinal, o que configura um sujeito-homem?

A cartografia toma emprestada da Geografia a noção de cartografar territórios que se movimentam e sua construção e tem em seu uso o emprego do ato de mapear um conceito até as suas últimas consequências, bem como da Botânica a noção de enraizamento oculto, que sustenta a genealogia e o sentido de árvore que se encontra em uma existência arraigada em um território existencial imerso no vivido ${ }^{18}$.

Para os geógrafos, a cartografia - diferentemente do mapa, representação de um todo estático - é um desenho que acompanha e se faz ao mesmo tempo em que os movimentos de transformação da paisagem. Paisagens psicossociais também são cartografáveis. A cartografia, nesse caso, acompanha e se faz ao mesmo tempo em que o desmanchamento de certos mundos - sua perda de sentido - e a formação de outros: mundos que se criam para expressar afetos contemporâneos, em relação aos quais os universos vigentes tornaram-se obsoletos. Sendo tarefa do cartógrafo dar língua para afetos que pedem passagem, dele se espera basicamente que esteja mergulhado nas intensidades de seu tempo e que, atento às linguagens que encontra, devore as que lhe parecerem elementos possíveis para a composição das cartografias que se fazem necessárias. O cartógrafo é antes de tudo um antropófago. (p. 15)

Assim, devemos discorrer acerca dos devires e por devir compreendemos, com Deleuze e Guattari $^{23}$, o conteúdo do desejo: desejar é, pois, passar por devires. Esse conceito é enunciado no Anti-Édipo, obra escrita como reação à psicanálise de Freud e Lacan (ainda muito influente na França) e que se propunha explorar novos caminhos para o inconsciente e o desejo. O devir deve ser entendido não como uma generalidade (não há devir em geral); esse conceito vincula-se à existência concreta e sempre singular. Nessa concepção, os devires são realidade, não se assemelham ao sonho ou ao imaginário, mas são a própria consistência do real. Outro ponto fundamental a se destacar, para se pensar o gênero masculino, é o fato de que todo devir é minoritário, sendo um elemento de variação que não se encaixa, que escapa, que se descola. A diferença é devir, conforme Deleuze e Guattari23, pois "por que há tantos devires do homem, mas não um devir-homem? É primeiro porque 
o homem é majoritário por excelência, enquanto que os devires são minoritários, todo devir é um devir minoritário" 23 (p. 87).

Essa colocação nos põe a pensar as ligações entre os devires e as micropolíticas, que nada têm a ver com a maioria, com o exercício do poder hegemônico. O que Deleuze e Guattarij3 nomeiam de "homem" não se refere a gênero ou a uma definição biológica do corpo. Essa noção diz respeito a um modo de organização do poder que se coloca enquanto pretenso polo determinante de dominação: "Por maioria nós não entendemos uma quantidade relativa maior, mas a determinação de um estado ou de um padrão em relação ao qual tanto as quantidades maiores quanto as menores serão ditas minoritárias [...] Maioria supõe um estado de dominação, não o inverso"23 (p. 87).

A potência dos devires passa pelos modos de vida minoritários e, assim, é possível falar em devirmulher, devir-criança e devir-animal. Não se trata de formas e sim do fluxo que constitui um corpo ${ }^{23}$. Os termos homem e mulher são genéricos e dizem respeito às políticas de gênero e identidade por meio da efetivação das conexões testamentais dessas formas e da produção de subjetividade capitalística ${ }^{24}$. Por outro lado, o devir-mulher é a tendência de um corpo que flui, dizendo respeito às alianças rizomáticas, afetivas, do Corpo sem Órgãos ( $\mathrm{CsO}$ ) e que fogem às políticas de identidade: uma matéria de odor conceitual pulsante na qual vibram e se movimentam os afetos.

Herdamos uma tradição em que há uma espécie de devir masculino presente na sociedade, em que os homens acabam por gozar de posições privilegiadas dentro da ordem societária ocidental, fruto do tangenciamento de questões como o patriarcalismo e o machismo. Podemos, então, falar de um fluxo masculino universal, por meio do qual, tradicionalmente, retira-se um decalque e se analisa todas as questões ${ }^{25}$.

A força da ordem masculina se evidencia no fato de que ela dispensa justificação: a visão androcêntrica impõe-se como neutra e não tem necessidade de se enunciar em discursos que visem a legitimá-la. A ordem social funciona como uma imensa máquina simbólica que tende a ratificar a dominação masculina sobre a qual se alicerça: é a divisão sexual do trabalho, distribuição bastante estrita das atividades atribuídas a cada um dos dois sexos, de seu local, seu momento, seus instrumentos; é a estrutura do espaço, opondo o lugar de assembleia ou de mercado, reservados aos homens, e a casa, reservada às mulheres; ou, no próprio lar, entre a parte masculina, com o salão, e a parte feminina, com o estábulo, a água e os vegetais; é a estrutura do tempo, as atividades do dia, o ano agrário, ou o ciclo de vida, com momentos de ruptura, masculinos, e longos períodos de gestação, femininos. (p. 24)

Destarte, o que Bourdieu ${ }^{25}$ assevera é a existência desse masculino universal, por meio do qual se depreendem circunstâncias socioculturais em que a potência de afecção masculina sobrepuja a condição feminina, caracterizando e materializando a dominação masculina e a violência simbólica.

Nesse cenário, emerge o devir-mulher, que se configura como a possibilidade de resistência e criatividade. Estar imerso no devir-mulher não significa ser uma mulher. O devir-mulher enuncia a imanência de se flutuar e derreter-se nos signos de maneira assignificante, produzindo linhas de fuga e de subjetividade ainda não capturadas e inventadas pela plástica e ética de existência capitalista e consumista, da moral cristã e do masculino universal. Seguindo esse raciocínio, afirmamos que apesar de o devir-mulher não fluir somente na mulher (compreendida genericamente como o humano nascido com uma vagina e com a sexualidade orientada de maneira feminina a se conceber enquanto mulher), não há um devir-homem! O homem já está posto; nesse sentido, não existe fuga.

O usuário-guia encontra-se na via do masculino universal. Não se esforça em manter as posições que lhe são concedidas dentro do tecido social, reverberando em seu cuidado. Demarquemos os seguintes aspectos: 1) sujeito-homem é dono de boa parte do quarteirão, no qual a sua companheira reside como inquilina; 2 ) é violento com todas as companheiras: com a mãe de Alva, a excompanheira que fugiu para o interior, e com a atual, usando um tom de voz imperativo e no caso das outras duas agressões, também, físicas; 3 ) por meio do medo, exerce poder sobre as companheiras e há uma espécie de cuidado agenciado por essas personagens, pois, apesar de não manterem contato direto, Maria ainda envia comida para sujeito-homem, Alva e Josefa disputam sobre quem cuida 
melhor e Eliana queria que ele ficasse em sua casa desde o início; 4) sujeito-homem não corta as próprias unhas e cabelos, não cozinha e exige que as companheiras e ex-companheiras o façam. Ou seja, goza do arquétipo do macho, que biopoliticamente gerencia as operações no território existencial das personagens de nossa história.

Todas essas demarcações versam uma construção do cuidado peculiar ao caso, tendo em vista que a ex-companheira fugiu e atualmente o papel de cuidadora é dividido entre Alva e Josefa.

[...] elas têm medo porque ele era violento demais [...] dos filhos ele gosta, mas as mulheres ele maltrata. [...] essa mulher foi embora [...] e ele ficou só, morando nessa casa, emagreceu, foi emagrecendo, definhando, as pessoas achavam até que era depressão, mas já era a doença. Aí essa mulher do lado, que era inquilina dele, Josefa, passou a namorar com ele. Aí foi quem começou a acompanhar o caso dele. (Alva)

Minha mãe ainda tem contato com ele, mas distante. Ela às vezes mandava comida [...] em marmitas [...], ele frequentava a casa da minha mãe mesmo depois de separados, ia lá e mandava a gente cortar a unha e o cabelo dele e a gente cortava... ele não corta as próprias unhas e cabelos. (Alva)

A gente se amigou, mas eu faço o que posso, né [...] contato mesmo de casal a gente não tem porque enfim... (Josefa)

Não se trata de falarmos acerca da história do homem e da mulher, de machismo ou feminismo - apesar de tangenciarmos tais questões - mas sim de pôr em questão a produção do cotidiano na perspectiva das afecções e de como isso reverbera na produção de saúde e no agenciamento de cuidado no SUS.

$\mathrm{Na}$ história de sujeito-homem, há uma quebra da rede formal, tendo em vista que o acesso do usuário é facilitado por profissionais familiares. De início, a médica de Uruburetama, sua sobrinha, de pronto entrou em contato com um primo que é médico oncológico e trabalha em um dos hospitais oncológicos da rede do município de Fortaleza e se prontificou a realizar as cirurgias gratuitamente. Após isso, o usuário adentra o SUS por meio do hospital de referência da rede privada e pela influência de Alva, que lá trabalha e facilitou seu acesso, conseguindo determinados materiais que eram necessários e tomando a responsabilidade pelo cuidado.

Os acompanhantes eram a Josefa, eu e meu irmão [...] acabei assumindo o cuidado [...] aí eu pedi pro doutor reencaminhar ele pra cá pra poder facilitar... tudo que fosse preciso fazer, rádio, químio... e como ele também é bem próximo eu teria acesso a ele também. Então [...] as dificuldades que a gente encontrou: foi o fato de ter que ser pelo SUS, mas facilitou porque eu trabalho aqui; a questão do cateter; ele teria que ter também umas bombas; a quimioterapia dele não é uma quimioterapia muito comum [...] eu nem tinha contato com esse tipo de tratamento. Então quando eu fui falar com Dr. Assis, ele falou "precisa de umas bombas e essas bombas são caras, se o SUS não cobrir você vai ter que comprar". Aí [...] conversei com a menina aqui do setor de administração e ela conseguiu incluir as bombas na PAC dele, o SUS cobriu. E o cateter eu recebi de doação [...] aí a gente pagou pro anestesista, chamamos o médico, que fez o favor de ir lá colocar, ele não cobrou nada pelo serviço. (Alva, filha)

Nesse aspecto, pomos o serviço em análise, uma vez que a rede formal não deu conta do fluxo de maneira efetiva, senão pela intervenção de personagens que não estavam relacionados diretamente com o protocolo. Isso talvez seja o principal demarcador desta pesquisa como um todo, uma vez que, ao se conceber a rede enquanto rizomática, agencia-se outros aspectos que escapam aos protocolos das políticas, estabelecendo linhas de fuga e as agenciando, a fim de garantir continuidade e integralidade do cuidado. A integralidade da atenção é ponto proeminente e que deve ser 
cotidianamente discutido de maneira séria e comprometida; é preciso que os serviços se adequem às necessidades de cuidado dos usuários, e não o contrário.

Assim, vemos a imanência da potência do corpo e a produção de seu cuidado ${ }^{12}$. É justamente sua rede informal, rede viva, combinada com a clínica dura do serviço, que operará essa potência e, no caso do macho, isso se faz peculiar, uma vez que os enunciados e agenciamentos presentes no masculino operam para a destruição da vida e para a opressão. No nosso caso, percebemos os traços patriarcalistas e machistas que reverberam na saúde e na rede existencial do usuário e dos personagens. O cuidado de si opera na via da violência com o corpo e com a subjetividade posta por modelos de subjetivação capitalísticas que sobrepujam a potência do corpo.

Foi necessário um diagnóstico de câncer, isto é, um balizamento, para se tensionar a questão da masculinidade do sujeito-homem. A mudança de hábitos ocorreu após o rearranjamento familiar do usuário, e quem está em questão nesta narrativa são precisamente as mulheres - entre elas, mulheresfilhas e mulheres-esposas -, que tangenciam os devires profissionais (mãe, filha, entre outros) e exercem a potência criativa na plasticidade de suas vidas a partir de um sujeito doente que traz em si toda a cartografia do falo e que, inclusive, fala muito alto com elas.

No mais, o usuário seguiu seu tratamento até o momento de encerramento deste escrito, debilitado, mas recusando-se, ainda, a um devir-doente, agarrando-se com todas as forças à potência de se afirmar perante a morte, excluindo-a de sua vivência. Neste escrito, a morte não é um ponto que possamos abordar com maior aprofundamento, mas é possível observar que esse movimento do sujeito aponta também para uma tentativa de estabelecer linhas de fuga, com o risco da desterritorialização, com os perigos que tal movimento implica: os das linhas de fuga se tornarem linhas de morte, daquilo que tem potencial para a criação tornar-se "pura abolição". Porém, a grande questão continua sendo a invenção de linhas de desterritorialização. A postura do sujeito-macho se caracteriza quase sempre pelo risco em forçar os limites; no caso, trata-se desse espectro existencial que leva embora quase todo o espírito e quase toda matéria... só é bom o que morre.

Sobre esses aspectos, convém discutirmos elementos de autores como Foucault e Deleuze. Foucault ${ }^{26,27}$ acerca da investigação sobre a sexualidade, relata uma maneira de se empregar os termos dispositivo das disposições sociais, agenciamentos e enunciados científicos, a fim de se compreender as práticas discursivas e não discursivas, apresentando sob um mesmo estatuto as instâncias do poder e saber em análise. Já Deleuze ${ }^{28}$ considera o dispositivo como um elemento conceitual plural e operatório agenciado nos aspectos de saber, poder e subjetivação (produção de modos de subjetivação). O que chamamos de dispositivo da sexualidade masculina ${ }^{1}$ refere-se a elementos presentes na configuração de um corpo afirmado na masculinidade.

Este diz respeito, por conseguinte, a um dispositivo agenciado na produção do cuidado. No âmbito da micropolítica, a enunciabilidade, que opera afecções - masculinidades - por meio do fio condutor do saber-poder engendrados em linhas de forças, desenvolvem práticas de saber e poder enunciadas no discurso do dispositivo da sexualidade masculina. Com isso, a partir da produção de subjetividade, são operadas linhas de subjetivação que anunciam desdobramentos criativos de possibilidades e descontinuidades do sujeito: linhas de fuga. A resistência é o que dá à fuga a condição de possibilidade e não se define como ruptura completa das formas de subjetivação propostas por regimes de saberpoder. É por meio das linhas de subjetivação que se delineiam configurações plásticas, fluxos e devires instituídos na imanência. A capacidade e possibilidade do empreendimento de linhas de fuga, de subversões e de estabelecimento de novas relações de força são operadas pelos próprios sujeitos.

Essa doença nem passou por aqui. Tô como sempre estive. Eu acordo cedo, águo as plantas, cuido aqui do meu jardim... tudo aqui fui eu que fiz. Pego o meu carro e saio, quero nem saber... e final do mês eu tô lá no forró, venha aqui pra você ver... próxima vez que você vier você vai ver. (Sujeito-homem)

Todo dispositivo se dá pela condição de novidade e criatividade, por meio da capacidade de transformar-se e de romper os limites impostos e criados por si e para si. Essa capacidade encontra- 
se engendrada ao desenho das linhas de subjetivação: uma vez articuladas em pontos de resistência imanentes e inerentes aos dispositivos, são linhas que produzem novas configurações saber-podersubjetividade, um novo ethos, podendo, portanto, antecipar dispositivos ${ }^{28}$.

Esses elementos do dispositivo da sexualidade masculina e do corpo de um sujeito-macho se apresentam como um sistema aberto (rizoma), que se constitui a partir de um jogo de forças produzido, desenvolvido e operacionalizado pelo engendramento de curvas e regimes, bem como por meio do conjunto de linhas do dispositivo da sexualidade masculina.

A partir da experiência do usuário-guia sujeito-homem, depreendemos que as linhas de força restauram as curvas de visibilidade e os regimes de enunciabilidade, reconfigurando suas bordas e cartografando caminhos que essas instâncias percorrerão: um eterno penetrar nas palavras e nas coisas.

Uma vez a masculinidade sendo admitida como domínio universalizado, diz-se de performances discursivas dominantes, ou até mesmo violentas, e também criativas. Diante disso, os processos decorrentes dessas linhas de força não reúnem sob um mesmo bojo um caráter objetificante de semelhanças entre as masculinidades - tal qual a presença genérica de um pênis -, mas sim enunciam as diferenças entre estas. O nosso esforço, portanto, versou sobre a concepção das masculinidades de maneiras hegemônicas advindas das estratégias discursivas do poder - e sua relação com o saber e a ética - e a identificação, nomeação de diferenças e possíveis fluxos esquizo. A diferença traz em seu bojo o fio condutor da produção de nomes e de singularizações e produz efeitos e verbos-forma: espetáculo. Vibra na frequência do corpo potente, engendrada nas relações de poder.

\section{Considerações finais}

O cuidado em saúde agencia diversos elementos micropolíticos. À guisa da integralidade da atenção, percebemos o esforço empreendido pelas normas, serviços e trabalhadores autogeridos em dar resposta e ordem a uma linha de cuidado com um sujeito ativo em situação clínica. Há o esforço biopolítico contemporâneo de se desenhar redes e comportar os corpos em um agenciamento enunciativo de cuidado visando a saúde. Mas em que medida nosso trabalho e formação asseguram tal perspectiva?

O usuário masculino apresenta necessidades específicas que, por vezes, os serviços de saúde não conseguem ou não se dispõem a acolher. Essa discussão já ocorre no campo da saúde do homem no Brasil, porém, as masculinidades encontram-se engendradas no dispositivo da sexualidade masculina, o que atravessa todo um regime de enunciabilidade corporificado no tecido social. Para se pensar a produção do cuidado ao usuário masculino, é necessário se pensar em uma clínica da diferença.

Há de se entender que o usuário é vivo: atua - assim como nós trabalhadores e pesquisadores - e, por conseguinte, participa da construção cotidiana do exercício da saúde coletiva no âmbito relacional. É, portanto, por meio da investigação micropolítica que podemos lançar luz sobre desafios que nos surgem acerca da integralidade. É por meio da experiência e da experimentação que podemos construir um sistema de saúde com os princípios éticos do SUS, expandir a clínica, inventar redes e viver a experimentação e autogestão do cotidiano de saúde.

Portanto, esse usuário muitas vezes lança mão de linhas de fuga a fim de combater as linhas de destruição societárias corporificadas nas políticas genéricas de identidade. O usuário trilha seu próprio caminho no jogo de possibilidades rizomático e imanente. O usuário é nômade e a clínica deve seguilo, e não guiá-lo. Assim, podemos empreender uma produção do cuidado integral. 


\section{Colaboradores}

Francisco Anderson Carvalho de Lima, Jonas Torres Medeiros, Túlio Batista Franco e Maria Salete Bessa Jorge participaram da elaboração intelectual, delineamento, levantamentos, análises e interpretações, discussão dos resultados, redação, revisão e aprovação da versão final a ser publicada. O autor principal realizou o trabalho de campo.

\section{Referências}

1. Lima FAC. Elementos cartográficos do macho: apontamentos sobre a(s) sexualidade(s) masculina(s) e gênero a partir da atenção oncológica de Fortaleza - um ensaio sobre a potência do corpo. [trabalho de conclusão de curso] Fortaleza: Universidade Estadual do Ceará; 2015.

2. Instituto Brasileiro de Geografia e Estatística. Brasil: tábua completa de mortalidade 2014 [Internet]. Rio de Janeiro: IBGE; 2014 [citado 27 Jan 2016]; 26. Disponível em: ftp://ftp.ibge.gov.br/Tabuas_Completas_de_Mortalidade/Tabuas_Completas_de_ Mortalidade_2014/notastecnicas.pdf.

3. Albuquerque GA, Leite MF, Belém JM, Nunes JNF, Oliveira MA, Adami F. O homem na atenção básica: percepções de enfermeiros sobre as implicações do gênero na saúde. Esc Anna Nery. 2014; 18(4):607-14. http://dx.doi.org/10.5935/1414-8145.20140086.

4. Bertolini DNP, Simonetti JP. O gênero masculino e os cuidados de saúde: a experiência de homens de um centro de saúde. Esc Anna Nery. 2014; 18(4):722-7. http://dx.doi. org/10.5935/1414-8145.20140103.

5. Cavalcanti JRD, Ferreira JA, Henriques AHB, Morais GSN, Trigueiro JVS, Torquato IMB. Assistência integral a saúde do homem: necessidades, obstáculos e estratégias de enfrentamento. Esc Anna Nery. 2014; 18(4):628-34. http://dx.doi.org/10.5935/14148145.20140089.

6. Moreira RLSF, Fontes WD, Barboza TM. Dificuldades de inserção do homem na atenção básica a saúde: a fala dos enfermeiros. Esc Anna Nery. 2014; 18(4):615-21. http://dx.doi. org/10.5935/1414-8145.20140087.

7. Ministério da Saúde (BR). Secretaria de Atenção à Saúde. Departamento de Ações Programáticas Estratégicas. Política Nacional de Atenção Integral à Saúde do Homem: princípios e diretrizes. Brasília; 2008 [citado 21 Jul 2016]. Disponível em: http://www. saude.ba.gov.br/novoportal/images/stories/saudedetodosnos/arquivos/politica_nacional_ atencao_saude_homem.pdf.

8. Yoshida VC, Andrade MGG. O cuidado à saúde na perspectiva de trabalhadores homens portadores de doenças crônicas. Interface (Botucatu). 2016; 20(58):597-610. http://dx.doi.org/10.1590/1807-57622015.0611.

9. Nascimento LV, Machado WD, Gomez DS, Vasconcelos MIO. Estudo de avaliabilidade da política nacional de atenção integral à saúde do homem no município de Sobral, Ceará. Rev Baiana Saude Publica. 2014; 38(1):95-114. https://doi.org/10.5327/Z0100-02332014380100015.

10. Leal AF, Figueiredo WS, Nogueira-da-Silva GS. O percurso da Política Nacional de Atenção Integral à Saúde dos Homens (PNAISH), desde a sua formulação até sua implementação nos serviços públicos locais de atenção à saúde. Cienc Saude Colet. 2012; 17(10):2607-16. http://dx.doi.org/10.1590/S1413-81232012001000010.

11. Deleuze G. Foucault. São Paulo: Brasiliense; 2005.

12. Franco TB, Galavote HS. Em busca da clínica dos afetos. In: Franco TB, Ramos VC, organizadores. Semiótica, afecção e cuidado em saúde. São Paulo: Hucitec; 2010. p. 176-99.

13. Merhy EE. Saúde: cartografia do trabalho vivo. São Paulo: Hucitec; 2002. 
14. Franco TB. Trabalho criativo e cuidado em saúde: um debate a partir dos conceitos de servidão e liberdade. Saude Soc. 2015; 24(1):102-14. http://dx.doi.org/10.1590/S0104$12902015 S 01009$.

15. Deleuze G, Guattari F. Mil platôs: capitalismo e esquizofrenia 2. 2a ed. São Paulo: Editora 34; 2014. v. 1.

16. Ferigato $\mathrm{SH}$, Carvalho SR. Pesquisa qualitativa, cartografia e saúde: conexões. Interface (Botucatu). 2011; 15(38):663-76. http://dx.doi.org/10.1590/S141432832011005000037

17. Martines WRV, Machado AL, Colvero LA. A cartografia como inovação metodológica na pesquisa em saúde. Rev Tempus Actas Saude Colet. 2013; 7(2):203-11. http://dx.doi. org/10.18569/tempus.v7i2.1354.

18. Rolnik S. Cartografia sentimental: transformações contemporâneas do desejo. São Paulo: Estação Liberdade; 1989.

19. Gomes MPC, Merhy EE, Silva E, Abrahão AL, Vianna L, Rocha M, et al. Uma pesquisa e seus encontros: a fabricação de intercessores e o conhecimento como produção. In: Gomes MPC, Merhy EE, organizadores. Pesquisadores IN-MUNDO: um estudo da produção do acesso e barreira em saúde mental. Porto Alegre: Rede Unida; 2014. p. $25-42$.

20. Deleuze G. Nietzsche. Lisboa: Edições 70; 2007.

21. Figueiredo W. Assistência à saúde dos homens: um desafio para os serviços de atenção primária. Cienc Saude Colet. 2005; 10(1):105-9. http://dx.doi.org/10.1590/S141381232005000100017.

22. Braz M. A construção da subjetividade masculina e seu impacto sobre a saúde do homem: reflexão bioética sobre justiça distributiva. Cienc Saude Colet. 2005; 10(1):97104. http://dx.doi.org/10.1590/S1413-81232005000100016.

23. Deleuze G, Guattari F. Mil platôs: capitalismo e esquizofrenia 2. 2a ed. São Paulo: Editora 34; 2012. v. 4.

24. Guattari F, Rolnik S. Micropolítica: cartografias do desejo. 7a ed. Petrópolis: Vozes; 2005.

25. Bourdieu P. A dominação masculina: a condição feminina e a violência simbólica. Rio de Janeiro: BestBolso; 2014.

26. Foucault M. História da sexualidade 1: a vontade de saber. 2a ed. São Paulo: Paz e Terra; 2015.

27. Foucault M. Sobre a história da sexualidade. In: Foucault M. Microfísica do poder. $23 a$ ed. Rio de Janeiro: Graal; 2007. p. 243-77.

28. Deleuze G. Que és un dispositivo? In: Balbier E, Dreyfus H, Deleuze G, Frank $M$, Glucksmann A. Michel Foucault, filósofo. Barcelona: Gedisa; 1999. p.155-63. 
Lima FAC, Medeiros JT, Franco TB, Jorge MSB. Género y sexualidad en Salud Colectiva: elementos para la discusión sobre la producción del cuidado integral para el usuario masculino. Interface (Botucatu). 2018; 22(64):29-41.

La garantía de la atención integral para el usuario masculino ha demostrado ser un gran desafío en el contexto de la Salud Colectiva. Se pretendió hacer la cartografía del macho para proporcionar contribuciones sobre la producción del cuidado al usuario masculino $y$, de esa forma, analizar el servicio formal de salud. Se utilizaron como fundamento Deleuze, Guattari, Foucault y Rolnik para pensar la cartografía, la discursividad y la subjetivación. Se utiliza el dispositivo del usuario-guía para cartografiar las redes recorridas formales e informales y para revelar los procesos relacionados a modos de subjetivación masculina. A partir de eso, se afirma la importancia de la potencia del cuerpo en la producción del cuidado en las redes vivas, la comprensión de la multiplicidad ( $n-1)$ materializada en la individualidad del cuidado de la potencia del afecto y la necesidad de reinvención de la clínica, así como la urgencia de la profundización de las discusiones sobre género y sexualidad en Salud Colectiva.

Palabras clave: Género y salud. Salud del hombre. Micro-política. 
